\title{
Experimental Study of the Multipactor Effect in a Partially Dielectric-Loaded Rectangular Waveguide
}

\author{
Andrés Berenguer, Ángela Coves, Senior Member, IEEE Benito Gimeno, Member, IEEE, \\ Enrique Bronchalo, and Vicente E. Boria, Fellow
}

\begin{abstract}
This letter presents the experimental study of the multipactor threshold in a partially dielectric-loaded rectangular waveguide, whose results validate a multipactor model recently developed by the authors, which includes the charge distribution appearing on the dielectric surface during the multipactor discharge. First, the variation of the multipactor RF voltage threshold has been theoretically analyzed in different waveguide configurations: in an empty waveguide, and also in the cases of a one-sided and two-sided dielectric-loaded waveguides. To reach this aim, an in-house Monte-Carlo simulation tool has been developed. The Secondary Electron Yield (SEY) of the metallic and dielectric materials used in the numerical simulations have been measured experimentally. Finally, an aluminum WR-75 symmetric E-plane rectangular waveguide transformer has been designed and fabricated, in which several multipaction tests have been carried out to validate the in-house software tool, demonstrating an excellent agreement between the simulation results and the experimental data.
\end{abstract}

Index Terms-Multipactor effect, RF breakdown, dielectric, rectangular waveguide, waveguide transformer, Secondary Electron Yield (SEY).

\section{INTRODUCTION}

$\mathbf{M}$ ULTIPACTOR is a well-known and undesired highpower effect affecting microwave components operating under high-vacuum conditions [1]. Such multipactoraffected components are present in a wide range of different scenarios, such as passive components of satellite communication payloads, klystrons, and particle accelerators. Multipactor consists of a generation of an electron avalanche that might result in a resonant discharge with harmful consequences for the involved device. Among these negative effects, it is worth mentioning the degradation of the component, detuning of resonant cavities, power dissipation, and a significant increase of noise in communications. Multipactor has been deeply investigated in several types of microwave waveguides with simple geometries, such as parallel-plate [1], rectangular [2][4], circular [5], elliptical [6], and coaxial waveguides [7], [8]. However, there are few contributions to the study of the multipactor effect in partially dielectric-loaded waveguides in the scenario of RF systems for space applications [9]-[12], and most of them use the parallel-plate waveguide approach. In a recent work of the authors [13], the multipactor effect in

A. Berenguer, Á. Coves and E. Bronchalo are with the Department of Communications Engineering, Universidad Miguel Hernández de Elche, Elche, Spain (e-mail: angela.coves@umh.es).

B. Gimeno is with the Department of Applied Physics and Electromagnetism-IFIC, Universidad de Valencia, Burjasot, Spain.

V. E. Boria is with the Departamento de Comunicaciones-ITEAM, Universitat Politècnica de València, Valencia, Spain. a partially dielectric-loaded rectangular waveguide has been analyzed from a theoretical point of view for the first time, considering both the RF fields inside the waveguide and the charge distribution appearing on the dielectric surface during the multipactor discharge. In order to validate the numerical method presented in [13] with experimental data, in this letter we present the multipactor threshold results on an aluminum WR-75 symmetric E-plane rectangular waveguide transformer, partially filled with a thin dielectric layer, specially designed for this experiment. The Secondary Emission Yield (SEY) properties of the different materials employed in this experiment have been measured and used in the numerical simulations. The variation of the multipactor RF voltage threshold has been theoretically analyzed for this waveguide with and without dielectric material, and its high power behaviour has been measured, demonstrating an excellent agreement between the simulated results and the experimental data.

\section{Simulation MOdel ANd SEY MEASUREMENTS}

In this work, the multipactor effect in a non-standard aluminum rectangular waveguide of width $a=19.05 \mathrm{~mm}$ and heigth $b=0.4 \mathrm{~mm}$, which is partially filled with a thin dielectric layer and corresponds to the central waveguide section of a symmetric E-plane waveguide transformer, has been analyzed and measured. To study the multipactor effect in this waveguide, a multipactor simulation code based on the Monte-Carlo method has been developed [13], which is an extension of previous studies of multipactor on a partially dielectric-loaded parallel-plate waveguide [9], [10]. In the employed multipactor code, both the RF and DC fields inside the waveguide have been rigorously considered, the last one being associated to the charge distribution appearing on the dielectric surface during the multipactor discharge. In order to determine this DC field, the electrostatic potential due to a unit point charge inside the waveguide has been first calculated by means of very efficient numerical summation and integration techniques [13]. Then, using the superposition principle, the electrostatic potential in the waveguide due to the set of charges on the dielectric surface can be obtained rigorously by adding the individual contribution of each charge, and finally the Edc field is obtained by numerical differentiation. The chosen dielectric film is DuPont Teflon ${ }^{\circledR}$ Fluorinated Ethylene Propylene (FEP) Fluoroplastic Film Type C [14], which is commonly used in space applications, with $\epsilon_{r}=2.1$ and a very small thickness $h=0.025 \mathrm{~mm}$. Therefore, the electrical performance of the waveguide transformer will scarcely be 


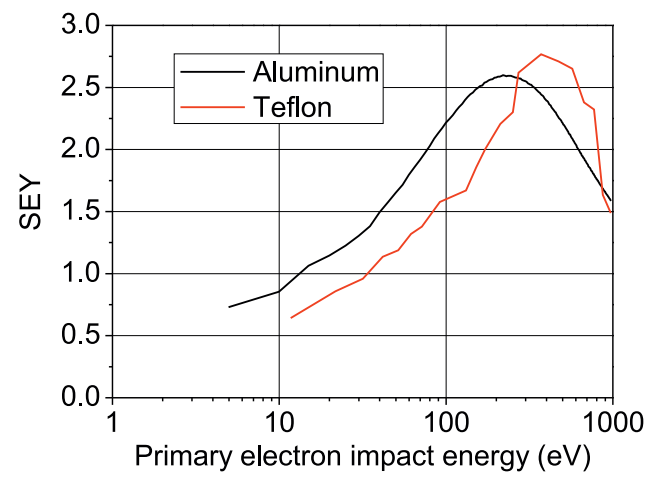

Fig. 1. SEY measured curves for the materials employed in this work.

modified when adding the dielectric film. It is well known that the SEY depends on material, primary electron kinetic energy, incident angle and surface state (surface composition, morphology of the structure, porosity and roughness) [15], [16]. The SEY properties of the metallic and dielectric materials employed in this experiment have been measured at the VSC/ESA laboratory, Valencia (Spain) [17], and they have been used in the multipactor simulations shown in the next section. For these materials, SEY at normal incidence was determined as a function of primary electron kinetic energy in the range $5-1000 \mathrm{eV}$, by measuring the sample current to ground when bombarded by a calibrated continuous primary electron beam of about $5 \mathrm{nA}$ in the case of aluminum. In the case of teflon, the measurement of the secondary electron emission was done by using an electron gun configured in pulsed mode for sending a single electron dose of less than $10^{6} \mathrm{e} / \mathrm{cm}^{2}$. After each dose, and before varying the primary electron energy, the sample was electrically neutralized.

Fig. 1 shows the measured SEY curves for aluminum and Teflon ${ }^{\circledR}$. It is worth mentioning that the maximum SEY of 2.8 measured for teflon is quite similar to the maximum SEY measured for aluminum (2.6). On the other hand, aluminum shows a lower first cross-over energy for the SEY curve $\left(W_{1}=\right.$ $15 \mathrm{eV})$ than the measured first cross-over value in teflon $\left(W_{1}=\right.$ $36 \mathrm{eV}$ ). These features are going to condition the multipactor results shown next.

\section{NUMERICAL AND EXPERIMENTAL RESULTS}

We have used the experimental SEY curves shown in Fig. 1 to compute the RF multipactor threshold voltage $V_{t h}$ in the aluminum rectangular waveguide of width $a=19.05 \mathrm{~mm}$ and heigth $b=0.4 \mathrm{~mm}$ under study, considering three different configurations: 1: without dielectric material; 2 : covering the bottom surface of the waveguide with a thin film of teflon (which has thickness $h=0.025 \mathrm{~mm}$ and $\epsilon_{r}=2.1$ ); 3: covering the top and bottom surfaces of the waveguide with teflon. Thus, the empty gap waveguide in the vertical dimension $d=b-h$ where the electrons can travel in each case will take values of $0.4,0.375$ and $0.35 \mathrm{~mm}$, respectively. In order to compute the multipactor RF $V_{t h}$ at a given $f \times d$ point, the same procedure used in [13] has been followed: for

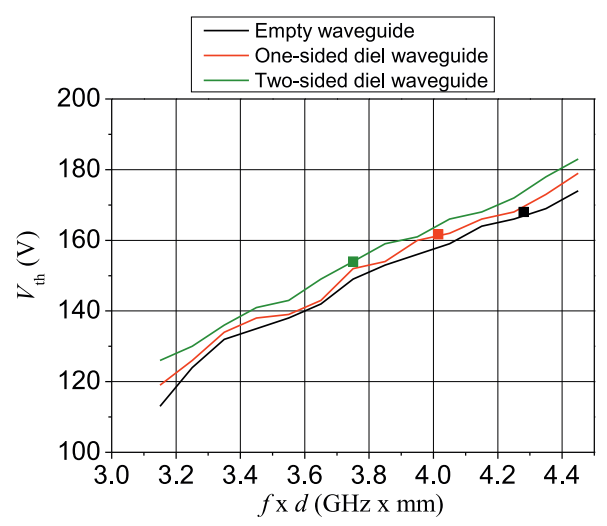

Fig. 2. RF Multipactor $V_{t h}$ of the rectangular waveguide for the three studied configurations. The squares correspond to the experimental data.

each $f \times d$ point, a sweep of the effective voltage $V_{\text {eff }}$ has been performed (calculated numerically as the line integral of the vertical component of the electric field, evaluated at the center of the waveguide and along the whole empty gap). For each $V_{\text {eff }}$, an statistical study of the final population of electrons after $100 \mathrm{RF}$ cycles is performed using a sufficiently high number of simulations, corresponding to different initial phases of the RF field. We have considered both the spread in secondary emission kinetic energy and angle of the secondary electrons after each impact on the waveguide walls. Such method has been used to estimate the RF multipactor $V_{t h}$ in the aforementioned three configurations as a function of $f \times d$, which is shown in Fig. 2 with lines. It can be checked that, for a given empty gap value $d=b-h$, the empty waveguide shows a slightly lower $V_{t h}$ than the one-sided and two-sided partially dielectric-loaded waveguides. Given that the field distribution is quite similar in all three cases, the observed difference in Fig. 2 is basically conditioned by the lower $W_{1}$ of aluminum $(15 \mathrm{eV})$ than that of Teflon $(36 \mathrm{eV})$, as already advanced in the previous section.

In order to validate the proposed model, a symmetric Eplane waveguide transformer has been designed and optimized (with Ansys HFSS) for a maximum return loss in the three aforementioned configurations at a frequency of $f=10.7$ $\mathrm{GHz}$, corresponding to the experimental test campaign to be performed in this waveguide. The scheme and final dimensions of the transformer are shown in Fig. 3 (note that the width of the involved rectangular waveguides is $a=19.05$ $\mathrm{mm})$. A photograph of the fabricated transformer is shown in Fig. 4. The measured S-parameters of this device in the three studied configurations are also shown in Fig. 5, where some discrepancies with simulations can be observed (a frequency shift towards lower frequencies of the minimum measured $S_{11}$ value, and also lower levels in the measured return losses in the three analyzed configurations). Nevertheless, the measured Sparameters of the three studied configurations still show very good matching levels (better than $20 \mathrm{~dB}$ ) and low insertion losses (lower than $0.3 \mathrm{~dB}$ ) from 10.4 to $10.77 \mathrm{GHz}$. This guarantees that the comparison of the experimental results with the simulations is valid at $f=10.7 \mathrm{GHz}$ (the frequency of the experimental multipactor test). 


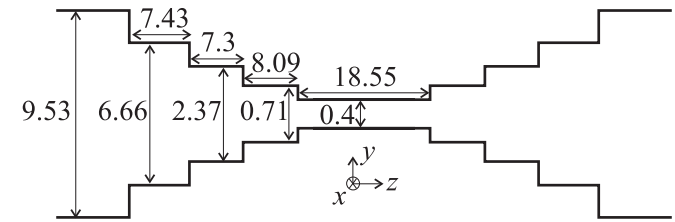

Fig. 3. Scheme of a symmetric E-plane rectangular waveguide transformer (dimensions in $\mathrm{mm}$ ).

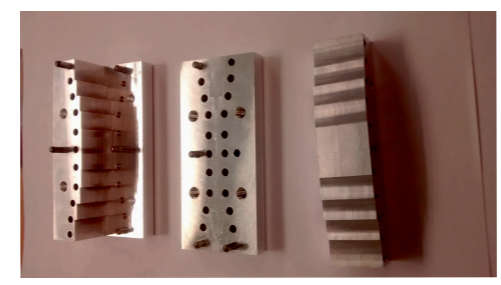

Fig. 4. Photograph of the fabricated E-plane rectangular waveguide transformer.

We have calculated the maximum effective voltage $\left(V_{\text {ef } f 1 W}\right)$ in the central section of the transformer (calculated from the maximum $y$ component of the electric field, as explained at the beginning of this section) in the three considered configurations, assuming an input power of $1 \mathrm{~W}$. Thus, a given RF input power $P_{i n p}$ can be related to the applied voltage in the critical gap region as $V_{\text {eff }}=V_{\text {eff } 1 W} \sqrt{P_{\text {inp }}}$. An experimental multipactor test campaign has been carried out at the VSC/ESA laboratory at the operational test frequency $f=10.707 \mathrm{GHz}$. The measured power levels at which the multipactor discharge was detected were $580 \mathrm{~W}$ (empty waveguide), $600 \mathrm{~W}$ (1 dielectric sheet) and $600 \mathrm{~W}$ (2 dielectric sheets), and the corresponding RF $V_{t h}$ values have been highlighted with squares in Fig. 2, showing an excellent agreement between the theoretical and the experimental data.

\section{CONCLUSION}

In this letter, the authors present the multipactor threshold results obtained for an aluminum WR-75 symmetric E-plane rectangular waveguide transformer, considering three configurations of the waveguide top and bottom walls: only metal, metal-dielectric, and only dielectric. The SEY properties of

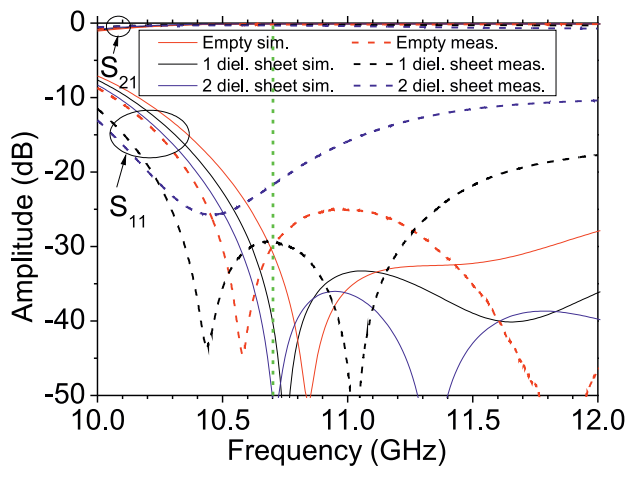

Fig. 5. Electrical response of the symmetric E-plane waveguide transformer. the different materials employed in this experiment have been measured and used in the numerical simulations. For this structure, the variation of the multipactor RF $V_{t h}$ has been theoretically analyzed (with and without dielectric material), and compared with multipaction measurements, demonstrating an excellent agreement between the theoretical and the experimental data. Both numerical and experimental results show the rise of the multipactor RF $V_{t h}$ at a given empty gap waveguide value when adding the dielectric material.

\section{ACKNOWLEDGMENT}

This work was supported by the Agencia Estatal de Investigación (AEI) and by the Unión Europea through the Fondo Europeo de Desarrollo Regional - FEDER - "Una manera de hacer Europa" (AEI/FEDER, UE), under the Research Projects TEC2016-75934-C4-2-R and TEC2016-75934-C4-1-R.

\section{REFERENCES}

[1] J. Vaughan, "Multipactor," IEEE Trans. Electron Devices, Vol. 35, No. 7, pp. 1172-1180, Jul. 1988, DOI: 10.1109/16.3387.

[2] V. E. Semenov, E. I. Rakova, D. Anderson, M. Lisak, and J. Puech, "Multipactor in rectangular waveguides," Phys. Plasmas, Vol. 14, No. 3, pp. 033501-1033501-8, 2007, DOI: 10.1063/1.2480678.

[3] C. Vicente, M. Mattes, D. Wolk, B. Mottet, H. L. Hartnagel, J. R. Mosig, and D. Raboso, "Multipactor breakdown prediction in rectangular waveguide based components," 2005 IEEE MTT-S International Microwave Symposium Digest, Long Beach, CA, USA, Jun. 2005, pp. 1055-1058, DOI: 10.1109/MWSYM.2005.1516852.

[4] E. Chojnacki, "Simulation of a multipactor-inhibited waveguide geometry," Physical Review Special Topics - Accelerators and Beams, Vol. 3, p. 032001, Mar. 2000, DOI 10.1103/PhysRevSTAB.3.032001.

[5] A. M. Pérez, V. E. Boria, B. Gimeno, S. Anza, C. Vicente, and J. Gil, "Multipactor analysis in circular waveguides," J. Electromagn. Waves Appl., Vol. 23, No. 11/12, pp. 1575-1583, 2009, DOI: $10.1163 / 156939309789476356$.

[6] A. Frotanpour, B. Gimeno, and S. Esfandiarpour, "Multipactor in dualmode elliptical waveguide," 31st International Review of Progress in Applied Computational Electromagnetics (ACES), Williamsburg, VA, USA, May 2015.

[7] A. M. Pérez, C. Tienda, C. Vicente, S. Anza, J. Gil, B. Gimeno, V. E. Boria, and D. Raboso, "Prediction of multipactor breakdown thresholds in coaxial transmission lines for traveling, standing, and mixed waves," IEEE Trans. Plasma Sci., Vol. 37, No. 10, pp. 2031-2040, Oct. 2009, DOI: $10.1109 /$ TPS.2009.2028428.

[8] D. González-Iglesias, O. Monerris, B. Gimeno, E. Díaz, V. E. Boria, and P. Martín-Iglesias, "Multipactor RF breakdown in coaxial transmission lines with digitally modulated signals," IEEE Trans. Electron Devices, Vol. 63, No. 10, pp. 4096-4103, Oct. 2016, DOI: 10.1109/TED.2016.2596801.

[9] G. Torregrosa, A. Coves, C. P. Vicente, A. M. Pérez, B. Gimeno, and V. E. Boria, "Time evolution of an electron discharge in a parallel-plate dielectric-loaded waveguide," IEEE Electron Device Lett., Vol. 27, No. 7, pp. 629-631, Jul. 2006, DOI: 10.1109/LED.2006.877284.

[10] A. Coves, G. Torregrosa-Penalva, C. P. Vicente, A. M. Pérez, B. Gimeno, and V. E. Boria, "Time evolution of an electron discharge in a parallel-plate dielectric-loaded waveguide," IEEE Trans. Electron Devices, Vol. 55, No. 9, pp. 2505-2511, Sep. 2008, DOI: 10.1109/LED.2006.877284.

[11] E. Sorolla, M. Belhaj, J. Sombrin, and J. Puech, "New multipactor dynamics in presence of dielectrics," IEEE Trans. Plasma Sci., Vol. 24, No. 10, p. 103508, 2017, DOI: 10.1063/1.5001832.

[12] G. Torregrosa-Penalva, A. Coves, B. Gimeno, I. Montero, C. Vicente, and V. E. Boria, "Multipactor susceptibility charts of a parallel-plate dielectric-loaded waveguide," IEEE Trans. Electron Devices, Vol. 57, No. 5, pp. 1160-1166, May. 2010, DOI: 10.1109/TED.2010.2043182.

[13] A. Berenguer, A. Coves, F. Mesa, E. Bronchalo, and B. Gimeno, "Analysis of multipactor effect in a partially dielectric-loaded rectangular waveguide," accepted in IEEE Trans. Plasma Science, DOI: 10.1109/TPS.2018.2880652.

[14] https://www.chemours.com/. 
[15] K. Nishimura, T. Itotani, and K. Ohya, "Influence of surface roughness on secondary electron emission and electron backscattering from metal surface," Jpn. J. Appl. Phys, Vol. 33, No. 8, pp. 4727-4734, Aug. 1994.

[16] E. Bronchalo, A. Coves, B. Gimeno, I. Montero, L. Galán, V. E. Boria. L. Mercadé, and Esteban Sanchís, "Secondary electron emission of Pt: experimental study and comparison with models in the multipactor energy range," IEEE Trans. Electron Devices, Vol. 63, No. 8, pp. 3270-3277, Aug. 2016, DOI: 10.1109/TED.2016.2580199.

[17] https://www.val-space.com/. 